\title{
The role of alexithymia in predicting incident depression in patients at first acute coronary syndrome
}

\author{
Carlo Marchesi $^{\mathrm{a}, \mathrm{b}, *}$, Paolo Ossola ${ }^{\mathrm{a}, \mathrm{b}}$, Francesca Scagnelli ${ }^{\mathrm{a}}$, Lorenzo Mellini ${ }^{\mathrm{a}}$, Matteo Tonna ${ }^{\mathrm{b}}$, \\ Diego Ardissino ${ }^{\mathrm{c}}$, Chiara De Panfilis ${ }^{\mathrm{a}, \mathrm{b}}$ \\ ${ }^{a}$ Department of Neuroscience, Psychiatry Unit, Università degli Studi di Parma, Parma, Italy \\ ${ }^{\mathrm{b}}$ Mental Health Department, AUSL, Parma, Italy \\ ${ }^{\mathrm{c}}$ Department of Cardiology, Azienda Ospedaliero-Universitaria di Parma, Parma, Italy
}

\begin{abstract}
Objective: Alexithymia has been considered both to predispose to depression and to worsen cardiac prognosis after an acute coronary syndrome. Nonetheless, no studies have evaluated its role as a risk factor for incident depression, in patients with acute coronary syndrome. Methods: In 251 consecutive patients, the presence of a first-ever depressive episode was evaluated with the Primary Care Evaluation of Mental Disorders at baseline and 1, 2, 4, 6, 9, 12 and 24 months after their first acute coronary syndrome. At baseline, patients completed the Toronto Alexithymia Scale (TAS-20) and the Hospital Anxiety and Depression Scale.

Results: Out of 251 subjects (80.9\% males), a first-ever depressive episode was diagnosed in 66 patients. Depressed and never-depressed patients differed in female gender, living status, alexithymic scores at TAS-20 and depressive symptoms. Nonetheless, nor the TAS-20 factors nor its total score were predictive of developing a depressive episode in a Cox regression. Moreover, baseline differences in TAS-20 scores between the two groups, disappeared after controlling for anhedonic symptoms.

Conclusion: Our results do not support the hypothesis that alexithymia at TAS-20 is a risk factor for incident depression after acute coronary syndrome.
\end{abstract}

(C) 2015 Elsevier Inc. All rights reserved.

\section{Introduction}

Alexithymia is a multidimensional construct characterized by an impoverished fantasy life, difficulty in expressing or naming feelings, difficulty distinguishing between bodily sensations and feelings and a preoccupation with external events [1]. The TAS-20 [2,3] is the most widely used and studied self-report measure of alexithymia. Factor analysis has supported a three-factor solution for this scale: (1) difficulty identifying feelings (DIF), (2) difficulty communicating and describing feelings (DDF), and (3) external-oriented thinking

\footnotetext{
* Corresponding author at: Department of Neuroscience, Psychiatry Unit, University of Parma, University Hospital, Braga Building, 43126 Parma, Italy. Tel.: +39 0521 903765; fax: +39 0521396825.

E-mail addresses: carlo.marchesi@unipr.it (C. Marchesi), paolo.ossola@unipr.it (P. Ossola), scagnelli.fra@libero.it (F. Scagnelli), lorenzomellini@gmail.com (L. Mellini),mtonna@ausl.pr.it (M. Tonna), dardissino@ao.pr.it (D. Ardissino), chiara.depanfilis@unipr.it (C. De Panfilis).
}

(EOT). Items representing impoverished fantasy or reduced daydreaming were dropped from the TAS-20 based on the factor analysis.

Alexithymia, reflecting a disordered affect regulation, is thought to increase vulnerability to several medical disorders, such as rheumatoid arthritis, essential hypertension, cardiac disease, stroke, peptic ulcer, inflammatory bowel disease, breast cancer, diabetes and kidney failure [4].

Moreover, high levels of alexithymia $[5,6]$ or high rates of alexithymic subjects (21-32\%) [7-9] were found in patients with coronary artery disease, suggesting that alexithymia could be a risk factor for it [10-12].

Alexithymia is also supposed to be a risk factor for the development of mental disorders, such as major depression $[1,13,14]$, panic disorder, eating disorders and substance use disorders $[15,16]$.

The association between depression and acute coronary syndrome is well-established [17] and depression is observed in $19.8 \%$ of patients who survive acute myocardial infarction [18]. 
Depression in patients with acute coronary syndrome is associated with a worse cardiac outcome [19] due to an increase recurrence of cardiac events and mortality [20]. Moreover, a specific type of depression [21], characterized by higher anhedonia levels, has been supposed to be specifically related to cardiac outcome $[22,23]$. Risk factors for the development of depression after acute coronary syndrome have been also identified: younger age [24]; female gender [25] low level of education [26]; low socio-economic status [27]; having no close friend [28]; being unemployed and living alone [29]; type D personality [30]; psychological vulnerabilities (i.e. exhaustion, fatigue, interpersonal difficulties, cognitive distortions) [31-33]; the presence of depressive symptoms in the few days after an acute coronary syndrome $[34,35]$; and the severity of the acute coronary syndrome [24,36,37].

To our knowledge, no study investigated in patients with acute coronary syndrome whether alexithymia predicted the development of major depression. Previous studies observed that alexithymia was significantly related with anxiety and depression in acute coronary syndrome patients $[9,11,38]$ and one study suggested that alexithymia is a consequence of acute myocardial infarction [38]. Furthermore, all the studies investigating alexithymia in coronary artery disease enrolled patients with previous episodes of coronary disease and most of these studies found an association between TAS-20 scores and pervious myocardial infarction or angina episodes $[6-8,38]$.

These findings questioned whether the TAS-20 could measure negative affects associated with a general distress syndrome [15] or with a depressive episode [39] induced by recurrent episodes of coronary disease rather than alexithymia itself.

Therefore, the aim of this study is to evaluate whether alexithymia predicted the development of depressive episodes in never depressed patients at their first acute coronary syndrome.

\section{Materials and methods}

\subsection{Sample}

The study sample was selected among patients who were consecutively admitted to an Italian Coronary Intensive Care Unit from January 2009 to March 2012, for an acute coronary syndrome.

The local ethic committee has approved the study protocol, all the participants gave their informed consent after the study was fully explained and the study has been conducted according the Helsinki Declaration.

Patients were included in the study if at the time of enrolment: (1) their age was over 18 years; (2) they were native Italian speaker or with a proficiency in Italian; (3) they had no previous or current major depressive episode according DSM-IV [40]; (4) they had no substance abuse or dependence; (5) they did not show cognitive impairment as demonstrated by a Mini Mental State Examination (MMSE) [41] lower than 25; and (6) they did not take any psychotropic medication. (7) They presented for the first time with symptoms suggestive of an acute coronary syndrome and in whom an ST-segment elevation myocardial infarction (STEMI), a non-ST-segment elevation myocardial infarction (NSTEMI), or unstable angina had been diagnosed $[24,43]$. The working diagnosis of NSTE-acute coronary syndrome was a rule-out diagnosis based on the ECG, i.e. lack of persistent ST elevation. Biomarkers (troponins) further distinguished NSTEMI and unstable angina [42].

\subsection{Assessment}

All patients underwent the following evaluations at baseline: (1) a brief socio-demographic interview; (2) the Primary Care Evaluation of Mental Disorder (PRIME-MD) [44] to diagnose current or previous depressive episodes; (3) the Hospital Anxiety and Depression Scale (HADS) [45] that generates two subscale scores: the anxiety score (HADS-A) and the depression score (HADS-D); and (4) the Toronto Alexithymia Scale, 20 items (TAS-20) [2,3]. The TAS-20 generated four scores: difficulty identifying feelings (DIF) score, difficulty describing, communicating and expressing feelings to others (DDF) score, externally oriented thinking (EOT) score and TAS-20 total scores. A total score higher than 60 has been proposed to define someone as alexithymic. In this sample, the internal consistency for the TAS total score was $\alpha=.77$; (5) they were assigned a GRACE score which assesses mortality risk after acute coronary events [46]. The Global Registry of Acute Coronary Events (GRACE) score [47] is based on a risk model of 6 months mortality risk from the time of hospital discharge; it considers age, history of MI, past or current congestive heart failure (CHF), heart rate, systolic blood pressure, serum creatinine, elevated cardiac enzymes, ST-segment depression on ECG at admission, and no in hospital percutaneous intervention (PCI). All the information concerning the abovementioned parameters was obtained from chart review at baseline. The GRACE score ranges between 1 and 263 points. A score of 80 predicts a $1 \%$ mortality rate at six months, 100 predicts a $2 \%$ mortality rate, and $>210$ predicts a $>50 \%$ mortality rate.

After the inclusion in the study, patients were re-evaluated one, two, four, six, nine, twelve and twenty-four months later with the PRIME-MD followed by a psychiatric interview to confirm a diagnosis a depressive episode.

\subsection{Treatment}

Concerning treatment of depression, patients with depressive symptoms were referred to a psychiatrist, and properly treated.

\subsection{Statistical analyses}

After computing the rates of patients classified as depressed and never-depressed over the course of follow-up, the baseline differences among groups were evaluated using 
Fisher's exact test for categorical variables (i.e., gender, educational, family and occupational status) and t-test with for continuous variables (i.e. age, GRACE score, HADS and TAS-20 scores).

Analysis of covariance (ANCOVA) was used to evaluate whether, at baseline, the difference in TAS-20 scores among groups remained after controlling for the effect of depressive symptoms.

Previous results in literature $[48,49]$ confirm the high correlation found between HADS-A and HADS-D $(r=.777$, $\mathrm{p}<0.001)$. In order to avoid collinearity between the covariates at the ANCOVA, we performed an exploratory factor analysis of HADS. It identified two main factors: a first factor named negative affectivity (HADS-NA) where loaded mainly the items exploring low mood and worries (items 1, 3, 5, 6, 8, 10,11 and 13) and a second factor named loss of pleasure or interest (HADS-LP) (items 2, 4, 7, 9, 12 and 14). Doing so, no more collinearity emerged between the two predictors (i.e. Tolerance $>.02$; VIF $<10 ; \mathrm{r}=.158$; $\mathrm{p}=0.01$; lower $\%$ of variance explained by the same small eigenvalue). Considering previous results $[22,23,50]$ that suggested that low positive affectivity (i.e. anhedonic symptoms) is a core feature of depression in cardiac populations, we used the score of HADS-LP as a covariate in ANCOVA.

The cumulative incidence of depressive episode has been calculated over the follow-up as one minus the KaplanMeier survival probability.

A proportional hazard model (Cox regression, enter method) was used to evaluate which socio-demographic and clinical variables at baseline predicted the development of a depressive disorder during the follow-up period. We collapsed the family status in living alone that remained significant between the two groups, whereas dividing the sample in employed and unemployed/retired the differences were not significant anymore. Therefore, we entered the presence of a depressive episode as the state variables and its onset as time variable, whereas gender, living alone and the TAS-20 have been entered as independent variables.

Since alexithymia is not a unitary construct we performed separate regressions for each sub-score (i.e. DDF, DIF and EOT) and for the total score.

We carried out all the analysis using SPSS software (version 21.0, IBM SPSS Statistics).

\section{Results}

\subsection{Patient characteristics}

Three-hundred-and-ninety-seven patients met the inclusion criteria, and among them, 377 agreed to participate in the study. During the follow-up period 111 patients dropped (25 moved outside the study area and 21 continued the rehabilitation treatment in a different hospital after the enrolment, 65 refused further psychiatric evaluations, 15 passed away). Therefore, the study sample included 251 subjects (female $\mathrm{n}=48,19.1 \%$ ), with a mean age of $61.3 \pm$ 10.9 years (range $32-87$ years).

\subsection{Depressive disorder}

Throughout the follow-up period, a depressive disorder was diagnosed in 66 patients (26.3\%), of which 26 with major depression and 40 with minor depression, whereas 185 (73.7\%) did not show any depressive disorder during the 2-years of follow-up. Onset of the depressive episode during the follow-up evaluation is shown in Fig. 1.

\subsection{Socio-demographic characteristics}

Female gender, being housewife and widowed were more frequent in the depressed group (Table 1).

\subsection{Alexithymia}

At baseline, the TAS-20 scores, except for DDF and EOT, were higher in depressed than in non-depressed patients with a small medium effect size (DIF: $d=0.47$; TAS total score: $\mathrm{d}=0.33$ ). Moreover, based on the odd ratio of the chi-square test, the odds of patients with a new depressive episode were 3 times higher if they were alexithymic than if they were not $\left(\chi^{2}(1)=8.7 ; p=0.006 ;\right.$ OR $\left.=2.97\right)$.

Nonetheless, among groups, the differences in TAS-20 scores disappeared after controlling for the effect HADS-LP scores (ANCOVA, DIF: $\mathrm{F}=4.25 ; \mathrm{df}=1248 ; \mathrm{p}=0.5$; partial $\eta^{2}=.008 ;$ TAS-20 total score: $\mathrm{F}=2.00 ; \mathrm{df}=$ 1248; $p=0.16$; partial $\eta^{2}=.016$ ).

\subsection{Predictors of development of a depressive disorder}

At the Cox regression any of the TAS-20 factors was a significant predictor of the onset of depression (Block 1: Female Gender $\mathrm{OR}=1.21 ; 95 \% \mathrm{CI}=0.72-2.05 ; \quad \chi^{2}=$ $0.52 ; \mathrm{p}=0.47 ;$ Block 2: Female Gender $\mathrm{OR}=1.22$; $95 \% \mathrm{CI}=0.72-2.07 ; \chi^{2}=0.53 ; \mathrm{p}=0.47$; Living Alone $\mathrm{OR}=0.97 ; 95 \% \mathrm{CI}=0.56-1.68 ; \quad \chi^{2}=0.01 ; \mathrm{p}=0.93$; Block 3: TAS scores, in the four Cox regressions respectively, DIF OR $=1.01 ; 95 \% \mathrm{CI}=0.96-1.05 ; \quad \chi^{2}=$ $0.09 ; \mathrm{p}=0.76 ;$ DDF $\mathrm{OR}=1.05 ; 95 \% \mathrm{CI}=0.99-1.12$; $\chi^{2}=2.80 ; \mathrm{p}=0.09 ;$ EOT $\mathrm{OR}=1.01 ; 95 \% \mathrm{CI}=0.95-$ $1.06 ; \chi^{2}=0.06 ; p=0.80 ;$ TAS-20 total score $\mathrm{OR}=1.01$; $\left.95 \% \mathrm{CI}=0.99-1.03 ; \chi^{2}=0.73 ; \mathrm{p}=0.39\right)$.

\section{Discussion}

The present study aimed to evaluate the role of alexithymia in predicting the first depressive episode (incident depression) in never-depressed patients after their first acute coronary syndrome.

All the previous studies evaluated alexithymia in patients with recurrent episodes of coronary artery disease and in this population alexithymia has been associated with previous myocardial infarction or angina episodes [6-8,38]. Moreover, in these patients alexithymia has also been related with 


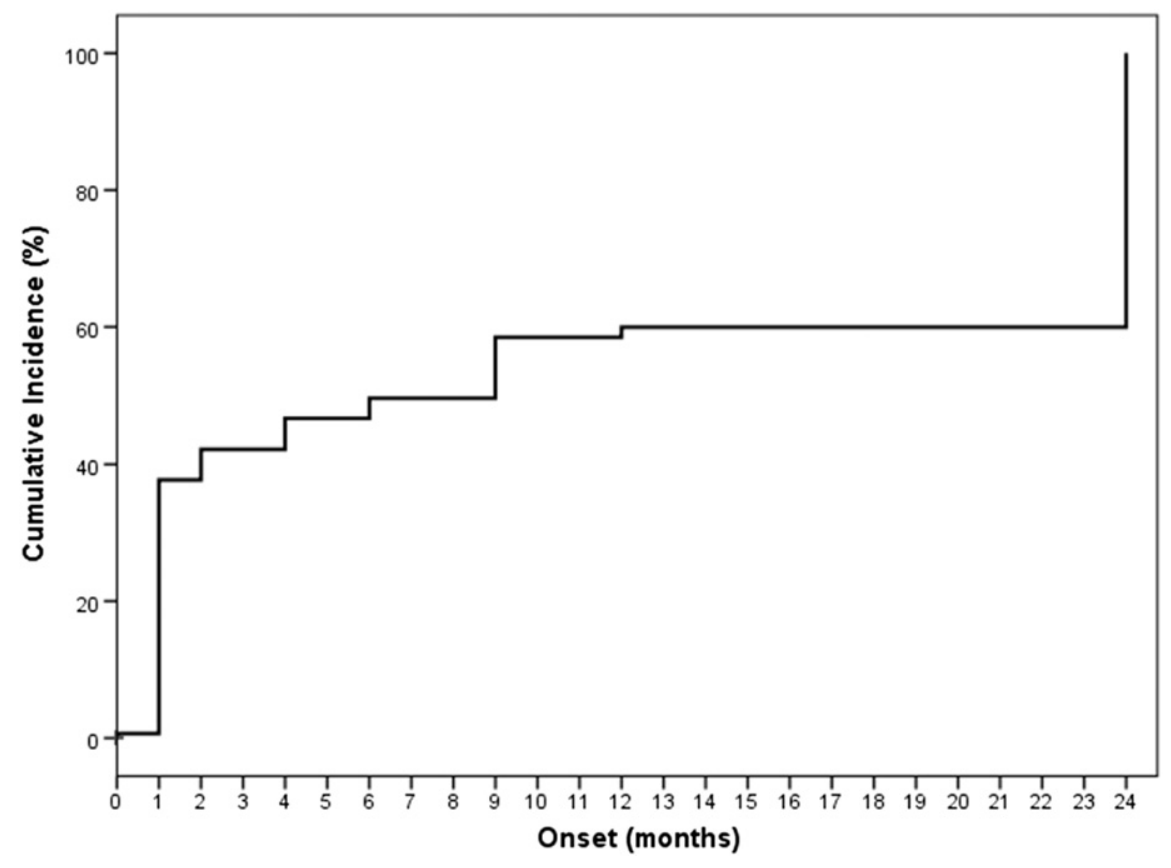

Fig. 1. Kaplan-Meier curve of the cumulative incidence, calculated as one minus survival, of depressive episodes $(\mathrm{n}=66)$ over the follow-up period $(2$ years $)$.

comorbid depression $[9,11,38]$. In contrast, in the present study alexithymia could not be associated at baseline with chronic coronary artery disease or with comorbid depression because only patients at their first acute coronary syndrome and without previous or current depressive episodes were enrolled.

In this study, patients who developed a depressive episode showed few days after their first acute coronary syndrome higher levels of DIF than subjects who maintained a non-depressed condition during the following year. Further, in those patients who developed depressive episode the rate of alexithymia at baseline was higher $(24.2 \%)$ than in those who did not $(9.7 \%)$, resulting in a three-fold increase in the risk of developing depression. Therefore, the TAS-20 scores assessed few days after an acute coronary syndrome and before the development of a depressive episode seem to increases the risk of depression, as suggested for patients without coronary artery disease [14,51-55].

Nevertheless, in the Cox regression analysis nor the TAS-20 total score at baseline nor the single factors predicted the development of a depressive episode.

There are at least two possible explanations for this finding.

Firstly, alexithymia may be a temporary response to a stressful condition, such as an acute coronary syndrome; in this view "secondary alexithymia" can represent a defense or a strategy to cope with distress (emotional pain, aversive memories and physiological arousal) associated with a life-threatening situation as previously hypothesized [38].

In the second hypothesis, the relationship between alexithymia and depression may represent an artifact of the method and measures used [63], since, particularly the TAS-20 dimensions DIF and DDF are associated with different measures of negative affects [15,16,56-63]. Therefore, individuals with negative emotional states (i.e. anxiety and depression) might score higher on these TAS-20 dimensions. This hypothesis is supported by previous studies, which found that alexithymia was significantly related with anxiety and depression in patients with an acute coronary syndrome $[9,11,38]$.

Specifically, in the present study, the baseline differences in the difficulty in identifying feelings between depressed and never-depressed, disappeared after controlling for anhedonic symptoms. This result confirm previous data in literature that suggest that this factor of TAS-20 measures mainly a secondary alexithymia related to anhedonic symptoms of depression [64], but not others that did not found an overlap between anhedonia and alexithymia in healthy subjects [65]. Nonetheless, even those features of alexithymia that should be less state-dependent (i.e. EOT) $[64,66]$, and not related to the anhedonic dimension in our sample $(r=.066 ; p=0.30)$ were not predictive of the development of depression.

The results of the present study do not support the notion that high TAS-20 scores increase the risk for developing a depressive disorder after an acute coronary syndrome, as already suggested in patients without coronary artery disease $[67,68]$. Instead, our results uphold the explanation that the assessment of alexithymia with TAS-20 few days after an acute coronary syndrome probably captures negative emotions following a life-threatening event. The data of this study also confirm the observation of significant relationships between alexithymia, assessed with the TAS-20, and negative affects or psychological distress 
Table 1

Socio-demographic characteristics of patients distinguished according to their depressive condition.

\begin{tabular}{|c|c|c|c|c|}
\hline & \multirow{2}{*}{$\frac{\text { Depression }}{\text { n. } 66}$} & \multirow{2}{*}{$\frac{\text { No Depression }}{\mathrm{n} .185}$} & \multirow[b]{3}{*}{$\mathrm{F}^{+}=7.2$} & \multirow[b]{3}{*}{$\mathrm{p}=0.01$} \\
\hline & & & & \\
\hline Gender (male) & $46(69.7 \%)$ & $157(84.9 \%)$ & & \\
\hline Age (years) & $62.6 \pm 10.7$ & $60.8 \pm 10.9$ & $F=0.3$ & $\mathrm{p}=0.26$ \\
\hline Education & & & $\mathrm{F}^{+}=1.3$ & $\mathrm{p}=0.73$ \\
\hline Primary school & $13(19.7 \%)$ & $31(16.8 \%)$ & & \\
\hline Lower secondary school & $21(31.8 \%)$ & $73(39.5 \%)$ & & \\
\hline Higher secondary school & $27(40.9 \%)$ & $67(36.2 \%)$ & & \\
\hline University & $5(7.6 \%)$ & $14(7.6 \%)$ & & \\
\hline Family status & & & $\mathrm{F}^{+}=9.9$ & $\mathrm{p}=0.02$ \\
\hline Never married & $7(10.6 \%)$ & $22(11.9 \%)$ & & \\
\hline Married & $42(63.6 \%)$ & $142(76.8 \%)$ & & \\
\hline Separated/divorced & $7(10.6 \%)$ & $13(7.0 \%)$ & & \\
\hline Widowed & $10(15.2 \%)$ & $8(4.3 \%)$ & & \\
\hline Living status (alone) & $18(27.3 \%)$ & $24(13.0 \%)$ & $\mathrm{F}^{+}=7.1$ & $\mathrm{p}=0.01$ \\
\hline Occupation & & & $\mathrm{F}^{+}=9.2$ & $\mathrm{p}=0.03$ \\
\hline Unemployed & $2(3.0 \%)$ & $3(1.6 \%)$ & & \\
\hline Retired & $33(50.0 \%)$ & $96(51.9 \%)$ & & \\
\hline Housewife & $7(10.6 \%)$ & $4(2.2 \%)$ & & \\
\hline Employed & $24(22.6 \%)$ & $82(44.3 \%)$ & & \\
\hline GRACE score & $130.7 \pm 29.0$ & $131.0 \pm 29.1$ & $\mathrm{~F}=0.07$ & $\mathrm{p}=0.93$ \\
\hline \multicolumn{5}{|l|}{ HADS scores at baseline } \\
\hline Anxiety & $9.27 \pm 4.5$ & $8.4 \pm 5.5$ & $F=20.7$ & $\mathrm{p}=0.22$ \\
\hline Depression & $8.33 \pm 4.1$ & $6.0 \pm 4.1$ & $\mathrm{~F}=0.73$ & $\mathrm{p}<0.001$ \\
\hline \multicolumn{5}{|l|}{ TAS-20 scores at baseline } \\
\hline DIF & $17.1 \pm 6.1$ & $14.2 \pm 5.5$ & $\mathrm{~F}=0.55$ & $\mathrm{p}=0.02$ \\
\hline$D D F$ & $13.5 \pm 4.2$ & $12.8 \pm 4.2$ & $\mathrm{~F}=0.01$ & $\mathrm{p}=0.19$ \\
\hline$E O T$ & $21.4 \pm 4.2$ & $21.0 \pm 4.4$ & $F=0.69$ & $\mathrm{p}=0.55$ \\
\hline Total & $52.1 \pm 12.1$ & $48.1 \pm 10.9$ & $\mathrm{~F}=0.59$ & $\mathrm{p}=0.02$ \\
\hline Total $>60$ & $16(24.2 \%)$ & $18(9.7 \%)$ & $\mathrm{F}^{+}=8.7$ & $\mathrm{p}=0.006$ \\
\hline
\end{tabular}

HADS (Hospital Anxiety and Depression Scale): anxiety and depression subscales.

TAS-20 (Toronto Alexithymia Scale, 20 items): DIF, difficulty identifying feelings; DDF, difficulty describing feelings, EOT, externally-oriented thinking. $\mathrm{F}=$ one-way ANOVA; $\mathrm{F}^{+}=$Fisher's exact test.

found in the general population $[56,69]$. Our data replicate the results of one of these studies [59] which found in the general population that the development of major depression was not predicted by TAS-20 score.

\subsection{Limitations}

Possible limitations of our study are the use of selfadministered scale of alexithymia [70], where a structured interview is more stable and consistently related to negative affects. Therefore, the findings of the present study, based only on a self-reported measure of alexithymia, need to be confirmed by researches using on observer ratings (e.g., Toronto Structured Interview for alexithymia) [71] or objective performance-based tasks such as the Levels of Emotional Awareness Scale [72].

Moreover, we cannot say when the feeling of anxiety and worries as much as the feelings of lack of pleasure or interest observed few days after the cardiac event appeared, specifically if their appearance preceded or followed the occurrence of the acute coronary syndrome. Regardless they represent a psychological disposition or a psychological reaction to an acute coronary syndrome, they do not satisfied at the time of inclusion in the study the diagnostic criteria for a major depressive episode.

\section{Conclusion}

The present study supports the hypothesis that the TAS-20, the most widely used self-administered scale assessing alexithymia, is overly sensitive to a general distress syndrome, and therefore it is more likely to measure negative affects (distress, nervousness, fear, anger, guilt, sadness, scornfulness) rather than alexithymia itself. In this view, patients after the first acute coronary syndrome reported high levels of alexithymia, assessed with TAS-20, because they present a psychological distress rather than a personality characterized by disordered affect regulation.

\section{Financial Support}

This research received no specific grant from any funding agency, commercial or not-for-profit sectors. 


\section{Conflict of Interest}

None.

\section{References}

[1] Taylor GJ, Bagby RM. New trends in alexithymia research. Psychother Psychosom 2004;73:68-77.

[2] Bagby RM, Parker JDA, Taylor GJ. The Twenty-Item Toronto Alexithymia Scale. I. Item selection and cross validation of the factor structure. J Psychosom Res 1994;38:23-32.

[3] Bagby RM, Parker JDA, Taylor GJ. The Twenty- Item Toronto Alexithymia Scale. II. Convergent, discriminant, and concurrent validity. J Psychosom Res 1994;38:33-40.

[4] Lumley MA, Neely LC, Burger AJ. The assessment of alexithymia in medical settings: implications for understanding and treating health problems. J Pers Assess 2007;89:230-46.

[5] Beresnevaité M. Exploring the benefits of group psychotherapy in reducing alexithymia in coronary heart disease patients: a preliminary study. Psychother Psychosom 2000;69:117-22.

[6] Kauhanen J, Kaplan GA, Cohen RD, Salonen R, Salonen JT. Alexithymia may influence the diagnosis of coronary heart disease Psychosom Med 1994;56:237-44.

[7] Beresnevaité M, Taylor GJ, Bagby RM. Assessing alexithymia and type A behavior in coronary heart disease patients: a multimethod approach. Psychother Psychosom 2007;76:186-92.

[8] Tolmunen T, Lehto SM, Heliste M, Kurl S, Kauhanen J. Alexithymia is associated with increased cardiovascular mortality in middle-aged Finnish men. Psychosom Med 2010;72:187-91.

[9] Valkamo M, Hintikka J, Niskanen L, Viinamäki H. Psychiatric morbidity and the presence and absence of angiographic coronary disease in patients with chest pain. Acta Psychiatr Scand 2001;104:391-6

[10] Parruti G, Vadini F, Sozio F, Mazzott E, Ursini T, Polill E, et al. Psychological factors, including alexithymia, in the prediction of cardiovascular risk in HIV infected patients: results of a cohort study. PLoS One 2013;8:e54555.

[11] Peters RM, Lumley MA. Relationship of alexithymia to cardiovascular disease risk factors among African Americans. Compr Psychiatry 2007:48:34-41

[12] Waldstein SR, Kauhanen J, Neumann SA, Katzel LI. Alexithymia and cardiovascular risk in older adults: psychosocial, psychophysiological, and biomedical correlates. Psychol Health 2002;17:597-610.

[13] Luminet O. Commentary on the paper "Is alexithymia a risk factor for major depression, personality disorder, or alcohol use disorders? A prospective population-based study". J Psychosom Res 2010;68:275-7.

[14] Saarijärvi S, Salminen JK, Toikka TB. Alexithymia and depression: a 1-year follow-up study in outpatients with major depression. J Psychosom Res 2001;51:729-33.

[15] Marchesi C, Ossola P, Tonna M, De Panfilis C. The TAS-20 more likely measures negative affects rather than alexithymia itself in patients with major depression, panic disorder, eating disorders and substance use disorders. Compr Psychiatry 2014;55:972-8.

[16] Marchesi C, Giaracuni G, Paraggio C, Ossola P, Tonna M, De Panfilis C. Pre-morbid alexithymia in panic disorder: a cohort study. Psychiatry Res 2014;215:141-5.

[17] Hare DL, Toukhsati SR, Johansson P, Jaarsma T. Depression and cardiovascular disease: a clinical review. Eur Heart J 2014:35:1365-72.

[18] Thombs BD, Bass EB, Ford DE, Stewart KJ, Tsilidis KK, Patel U, et al. Prevalence of depression in survivors of acute myocardial infarction. J Gen Intern Med 2006;21:30-8.

[19] Lichtman JH, Froelicher ES, Blumenthal JA, Carney RM, Doering LV, Frasure-Smith N, et al. Depression as a risk factor for poor prognosis among patients with acute coronary syndrome: systematic review and recommendations: a scientific statement from the American Heart Association. Circulation 2014;129:1350-69.
[20] Nicholson A, Kuper H, Hemingway H. Depression as an aetiologic and prognostic factor in coronary heart disease: a meta-analysis of 6362 events among 146538 participants in 54 observational studies. Eur Heart J 2006;27:2763-74.

[21] Granville Smith I, Parker G, Cvejic E, Vollmer-Conna U. Acute coronary syndrome-associated depression: the salience of a sickness response analogy? Brain Behav Immun 2015, http://dx.doi.org/ 10.1016/j.bbi.2015.02.025 [ahead of print].

[22] Leroy M, Loas G, Perez-Diaz F. Anhedonia as predictor of clinical events after acute coronary syndromes: a 3-year prospective study. Compr Psychiatry 2010;51:8-14.

[23] Pelle AJ, Pedersen SS, Erdman RA, Kazemier M, Spiering M, van Domburg RT, et al. Anhedonia is associated with poor health status and more somatic and cognitive symptoms in patients with coronary artery disease. Qual Life Res 2011;20:643-51.

[24] van Melle JP, de Jonge P, Kuyper AM, Honig A, Schene AH, Crijns $\mathrm{HJ}$, et al. Prediction of depressive disorder following myocardial infarction data from the Myocardial INfarction and DepressionIntervention Trial (MIND-IT). Int J Cardiol 2006;109:88-94.

[25] Doyle F, McGee H, Conroy R, Conradi HJ, Meijer A, Steeds R, et al. Systematic review and individual patient data meta-analysis of sex differences in depression and prognosis in persons with myocardial infarction: a MINDMAPS Study. Psychosom Med 2015;77:419-28, http://dx.doi.org/10.1097/PSY.0000000000000174.

[26] Carney RM, Freedland KE, Steinmeyer B, Blumenthal JA, de Jonge P, Davidson KW, et al. History of depression and survival after acute myocardial infarction. Psychosom Med 2009;71:253-9.

[27] Steptoe A, Molloy GJ, Messerly-Bürgy N, Wikman A, Randall G, Perkins-Porras L, et al. Emotional triggering and low socio-economic status as determinants of depression following acute coronary syndrome. Psychol Med 2011;41:1857-66.

[28] Frasure-Smith N, Lespérance F, Gravel G, Masson A, Juneau M, Talajic M, et al. Social support, depression, and mortality during the first year after myocardial infarction. Circulation 2000;101:1919-24.

[29] Larsen KK, Christensen B, Søndergaard J, Vestergaard M. Depressive symptoms and risk of new cardiovascular events or death in patients with myocardial infarction: a population-based longitudinal study examining health behaviors and health care interventions. PLoS One 2013:8:e74393

[30] Martens EJ, Smith OR, Winter J, Denollet J, Pedersen SS. Cardiac history, prior depression and personality predict course of depressive symptoms after myocardial infarction. Psychol Med 2008;38:257-64.

[31] Denton EG, Rieckmann N, Davidson KW, Chaplin WF. Psychosocial vulnerabilities to depression after acute coronary syndrome: the pivotal role of rumination in predicting and maintaining depression. Front Psychol 2012;3:288.

[32] Doyle F, McGee H, Delaney M, Motterlini N, Conroy R. Depressive vulnerabilities predict depression status and trajectories of depression over 1 year in persons with acute coronary syndrome. Gen Hosp Psychiatry 2011;33:224-31.

[33] Stafford L, Jackson HJ, Berk M. Cognitive-personality style as vulnerability to depression in patients with coronary artery disease: roles of sociotropy and autonomy. Psychosom Med 2009;71:63-9.

[34] Di Benedetto M, Lindner H, Hare DL, Kent S. The role of coping, anxiety, and stress in depression post-acute coronary syndrome. Psychol Health Med 2007;12:460-9.

[35] Marchesi C, Ossola P, Scagnelli F, Paglia F, Aprile S, Monici A, et al. Type D personality in never-depressed patients and the development of major and minor depression after acute coronary syndrome. J Affect Disord 2014;155:194-9.

[36] de Jonge P, van den Brink RH, Spijkerman TA, Ormel J. Only incident depressive episodes after myocardial infarction are associated with new cardiovascular events. J Am Coll Cardiol 2006;48:2204-8.

[37] Lespérance F, Frasure-Smith N, Juneau M, Théroux P. Depression and 1-year prognosis in unstable angina. Arch Intern Med 2000;160:1354-60 
[38] Kojima M, Frasure-Smith N, Lespérance F. Alexithymia following myocardial infarction: psychometric properties and correlates of the Toronto Alexithymia Scale. J Psychosom Res 2001;51:487-95.

[39] Marchesi C, Bertoni S, Cantoni A, Maggini C. Is alexithymia a personality trait increasing the risk of depression? A prospective study evaluating alexithymia before, during and after a depressive episode. Psychol Med 2008;38:1717-22.

[40] American Psychiatric Association. Diagnostic and statistical manual of mental disorders. 4th edit. Washington: American Psychiatric Association; 1994.

[41] Folstein MF, Folstein SE, McHugh PR. "Mini-mental state". A practical method for grading the cognitive state of patients for the clinician. J Psychiatr Res 1975;12:189-98.

[42] Hamm CW, Bassand JP, Agewall S, Bax J, Boersma E, Bueno H, et al. ESC guidelines for the management of acute coronary syndromes in patients presenting without persistent ST-segment elevation: the Task Force for the management of acute coronary syndromes (ACS) in patients presenting without persistent ST-segment elevation of the European Society of Cardiology (ESC). Eur Heart J 2011;32:2999-3054.

[43] Van deWerf F, Bax J, Betriu A, Blomstrom-Lundqvist C, Crea F, Falk $\mathrm{V}$, et al. Management of acute myocardial infarction in patients presenting with persistent ST-segment elevation: the Task Force on the Management of ST-Segment Elevation Acute Myocardial Infarction of the European Society of Cardiology. Eur Heart J 2008;29:2909-45.

[44] Spitzer RL, Williams JB, Kroenke K, Linzer M, deGruy FV, Hahn SR, et al. Utility of a new procedure for diagnosing mental disorders in primary care. The PRIME-MD 1000 study. JAMA 1994;272:1749-56.

[45] Zigmond AS, Snaith RP. The hospital anxiety and depression scale. Acta Psychiatr Scand 1983;67:361-70.

[46] Kronish IM, Rieckmann N, Schwartz JE, Schwartz DR, Davidson KW. Is depression after an acute coronary syndrome simply a marker of known prognostic factors for mortality? Psychosom Med 2009;71:697-703.

[47] Eagle KA, Lim MJ, Dabbous OH, Pieper KS, Goldberg RJ, Van de Werf $\mathrm{F}$, et al. A validated prediction model for all forms of acute coronary syndrome: estimating the risk of 6-month postdischarge death in an international registry. JAMA 2004;291:2727-33.

[48] Cosco TD, Doyle F, Ward M, McGee H. Latent structure of the Hospital Anxiety And Depression Scale: a 10-year systematic review. J Psychosom Res 2012;72:180-4.

[49] Burns A, Höfer S, Curry P, Sexton E, Doyle F. Revisiting the dimensionality of the Hospital Anxiety and Depression Scale in an international sample of patients with ischaemic heart disease. J Psychosom Res 2014;77:116-21.

[50] Honkalampi K, Hintikka J, Saarinen P, Lehtonen J, Viinamäki H. Is alexithymia a permanent feature in depressed patients? Psychother Psychosom 2000;69:303-8.

[51] Honkalampi K, Hintikka J, Antikainen R, Lehtonen J, Viinamäki H. Alexithymia in patients with major depressive disorder and comorbid cluster C personality disorders: a 6-month follow-up study. J Pers Disord 2001;15:245-54.

[52] Honkalampi K, Hintikka J, Laukkanen E, Lehtonen J, Viinamäki H. Alexithymia and depression. A perspective study of patients with major depressive disorder. Psychosomatics 2001;42:229-34.

[53] Honkalampi K, Koivumaa-Honkanen H, Antikainen R, Haatainen K, Hintikka J, Viinamäki H. Relationships among alexithymia, adverse childhood experiences, sociodemographic variables, and actual mood disorder: a 2-year clinical follow-up study of patients with major depressive disorder. Psychosomatics 2004;45:197-204.
[54] Luminet O, Bagby RM, Taylor GJ. An evaluation of the absolute and relative stability of alexithymia in patients with major depression. Psychother Psychosom 2001;70:254-60.

[55] Saarijärvi S, Salminen JK, Toikka TB. Temporal stability of alexithymia over a five-year period in outpatients with major depression. Psychother Psychosom 2006;75:107-12.

[56] Lumley MA. Alexithymia and negative emotional conditions. J Psychosom Res 2000;49:51-4.

[57] De Panfilis C, Ossola P, Tonna M, Catania L, Marchesi C. Finding words for feelings: the relationship between personality disorders in alexithymia. Pers Individ Differ 2015;74:285-91.

[58] Hintikka J, Honkalampi K, Lehtonen J, Viinamäki H. Are alexithymia and depression distinct or overlapping constructs? A study in a general population. Compr Psychiatry 2001;42:234-9.

[59] Honkalampi K, Koivumaa-Honkanen H, Lehto SM, Hintikka J, Haatainen K, Rissanen T, et al. Is alexithymia a risk factor for major depression, personality disorder, or alcohol use disorders? A prospective population-based study. J Psychosom Res 2010;68:269-73.

[60] Marchesi C, Brusamonti E, Maggini C. Are alexithymia, depression, and anxiety distinct constructs in affective disorders? J Psychosom Res 2000;49:43-9.

[61] Marchesi C, Fontò S, Balista C, Cimmino C, Maggini C. Relationship between alexithymia and panic disorder: a longitudinal study to answer an open question. Psychother Psychosom 2005;74:56-60.

[62] Marchesi C, Bertoni S, Maggini C. Major and minor depression in pregnancy. Obstet Gynecol 2009;113:1292-8.

[63] Ozsahin A, Uzun O, Cansever A, Guicat Z. The effect of alexithymic features on response to antidepressant medication in patients with major depression. Depress Anxiety 2003;18:62-6.

[64] Loas G, Dhee-Perot P, Chaperot C, Fremaux D, Gayant C, Boyer P. Anhedonia, alexithymia and locus of control in unipolar major depressive disorders. Psychopathology 1998;31:206-12.

[65] Loas G, Fremaux D, Boyer P. Anhedonia and alexithymia: distinct or overlapping constructs. Percept Mot Skills 1997;84:415-25.

[66] Wise TN, Mann LS, Randell P. The stability of alexithymia in depressed patients. Psychopathology 1995;28:173-6.

[67] Conrad R, Wegener I, Imbierowicz K, Liedtke R, Geiser F. Alexithymia, temperament and character as predictors of psychopathology in patients with major depression. Psychiatry Res 2009;165:137-44.

[68] Grabe HJ, Spitzer C, Freyberger HJ. Alexithymia and personality in relation to dimensions of psychopathology. Am J Psychiatry 2004;161:1299-301.

[69] Deno M, Miyashita M, Fujisawa D, Nakajima S, Ito M. The relationships between complicated grief, depression, and alexithymia according to the seriousness of complicated grief in the Japanese general population. J Affect Disord 2011;135:122-7.

[70] Inslegers R, Vanheule S, Meganck R, Debaere V, Trenson E, Desmet $M$. Interpersonal problems and cognitive characteristics of interpersonal representations in alexithymia: a study using a self-report and interview-based measure of alexithymia. J Nerv Ment Dis 2012;200:607-13.

[71] Bagby RM, Taylor GJ, Parker JDA, Dickens SE. The development of the Toronto Structured Interview for Alexithymia: item selection, factor structure, reliability and concurrent validity. Psychother Psychosom 2006;75:25-39.

[72] Lane R, Quinlan D, Schwartz G, Walker P, Zeitlin S. The levels of emotional awareness scale: a cognitive-developmental measure of emotion. J Pers Assess 1990;55:124-34. 